\title{
Factors associated with gestational weight gain: a cross-sectional survey
}

\author{
Edyta Suliga ${ }^{{ }^{*}}$ (D) Wojciech Rokita ${ }^{2}$, Olga Adamczyk-Gruszka² ${ }^{2}$ Grażyna Pazera ${ }^{3}$, Elżbieta Cieśla ${ }^{4}$ and \\ Stanisław Głuszek ${ }^{5}$
}

\begin{abstract}
Background: The aim of this study was to describe the dietary patterns in pregnant women and determine the association between diet factors, pre-pregnancy body mass index, socio-demographic characteristics and gestational weight gain.

Methods: The analysis was conducted on a group of 458 women. Cut-off values of gestational weight gain adequacy were based on recommendations published by the US Institute of Medicine and were body mass index-specific. Logistic regression analysis was used to assess the risk of the occurrence of inadequate or excessive gestational weight gain. Dietary patterns were identified by factor analysis.

Results: Three dietary patterns characteristic of pregnant women in Poland were identified: 'unhealthy', 'varied' and 'prudent'. The factor associated with increased risk of inadequate gestational weight gain was being underweight pre-pregnancy $(O R=2.61 ; p=0.018)$. The factor associated with increased risk of excessive weight gain were being overweight or obese pre-pregnancy $(\mathrm{OR}=7.00 ; p=0.031)$ and quitting smoking $(\mathrm{OR}=7.32 ; p=0.019)$. The risk of excessive weight gain was decreased by being underweight pre-pregnancy $(\mathrm{OR}=0.20 ; p=0.041)$, being in the third or subsequent pregnancy compared to being in the first $(\mathrm{OR}=0.37 ; p=0.018)$, and having a high adherence to a prudent dietary pattern $(\mathrm{OR}=0.47 ; p=0.033)$.

Conclusions: Women who were overweight or obese pre-pregnancy and those who quit smoking at the beginning of pregnancy should be provided with dietary guidance to prevent excessive gestational weight gain.
\end{abstract}

Keywords: Dietary patterns, Body mass index, Excessive weight gain

\section{Background}

Abnormal gestational weight gain (GWG) is currently a serious obstetric problem. The prevalence of inadequate GWG varies among populations. In the US, GWG was within the recommended range for $32 \%$ of women giving birth to full-term babies. In $48 \%$ of cases, the increase in weight was higher, and in $21 \%$ of the cases, weight gain was lower than that recommended by the US Institute of Medicine (IOM) [1, 2]. A survey conducted between 2006 and 2015 on over 18,000 women in rural Pennsylvania showed that only $25.3 \%$ of women in this population gained weight within the recommended range $-21.3 \%$ gained an amount below and $52.9 \%$ gained an amount

\footnotetext{
* Correspondence: edyta.suliga@ujk.edu.pl

${ }^{1}$ Department of Nutrition and Dietetics, Faculty of Medicine and Health

Sciences, Jan Kochanowski University, Kielce, Poland

Full list of author information is available at the end of the article
}

above the range in the IOM guidelines [3]. In a group of over 14,000 Italian women, the recommended GWG was found in $40.8 \%$, in $30.1 \%$ of the women, GWG was lower, and in $29.1 \%$, it was higher than the guidelines [4]. In German studies, $37.0 \%$ of women had excessive and $27.4 \%$ had inadequate GWG, according to the US IOM criteria [5]. Studies conducted in Poland showed that 40 to $48 \%$ of patients attain a GWG above the IOM guidelines and 14 to $23 \%$ attain a lower GWG $[6,7]$.

Abnormal GWG can have significant importance for both short-term pregnancy outcomes $[1,8,9]$ and for the long-term health of the offspring [10-13] and the mother $[8,14,15]$. Health risks related to inadequate weight gain during pregnancy involve, first and foremost, a greater risk of premature birth and a low birth weight baby and/or intrauterine hypotrophy and, consequently, an increased risk of mortality and morbidity $[1,9,16]$.

(c) The Author(s). 2018 Open Access This article is distributed under the terms of the Creative Commons Attribution 4.0 International License (http://creativecommons.org/licenses/by/4.0/), which permits unrestricted use, distribution, and reproduction in any medium, provided you give appropriate credit to the original author(s) and the source, provide a link to the Creative Commons license, and indicate if changes were made. The Creative Commons Public Domain Dedication waiver (http://creativecommons.org/publicdomain/zero/1.0/) applies to the data made available in this article, unless otherwise stated. 
Excessive weight gain is indicated as a risk factor for giving birth to a high birth weight baby compared with its gestational age $[9,17]$, giving birth to a baby with macrosomia $[4,9,18]$, gestational diabetes $[19,20]$, pregnancy-induced hypertension [21, 22], caesarean delivery [23, 24], longer infant hospital stays [22] and the persistence of a higher postpartum weight for the mother after childbirth, which predisposes one to obesity later in life $[8,14,15,25,26]$.

Maternal pre-pregnancy body mass index (BMI) [1, 27], diet [28-30], physical activity [27, 29], smoking status [31] and socio-demographic factors $[1,32-34]$ are listed as the main determinants of GWG. Women who were overweight or obese prior to pregnancy were significantly more likely to exceed weight guidelines $[1,27,34]$. Tielemans et al. [35] confirmed that specific dietary patterns (DP) may play a role in early pregnancy but are not consistently associated with GWG. In the meta-analysis carried out by Streuling et al. [28], five studies suggested significant positive associations between energy intake and GWG, whereas three found no significant associations. Women who remain physically active during their pregnancies have a lower risk for excessive weight gain $[27,29]$. However, some of the studies did not confirm any significant associations between physical activity and GWG [36, 37]. Current smokers are at an increased risk for insufficient weight gain, and former smokers are at an increased risk for excess GWG, compared to women who have never smoked [31]. It is worth noting that some studies did not confirm the relationship between smoking and GWG [38]. Therefore, the relationship between lifestyle and GWG is inconclusive.

Studies of the impact of socio-economic factors on GWG show that in the US, women with lower incomes gained more than the recommended weight compared to women with higher incomes [31, 39]. Women with less than a high school education had higher odds of inadequate GWG [40]. Huynh et al. showed that having a college or higher education was associated with a decreased GWG for non-Hispanic white women, but an increased GWG for Hispanic women [41]. Abbasalizad Farhangi states that in Iran women with high educational attainment have a significantly higher GWG compared with low-educated women [32]. As we can see, the presented research results are ambiguous and indicate that the risk of incorrect GWG in different populations may be determined by various cultural and socio-economic factors. Thus, they should always be taken into account when examining weight gain in pregnant women.

Very few papers have been published on GWG within the Polish female population $[6,7,42]$, and the relationship between dietary patterns and GWG has not been studied thus far. Dietary patterns are specific to particular populations, since they may vary with age, sex, ethnicity, cultural traditions, socioeconomic status, and food availability. Research confirms that there are important differences in dietary habits between and within Eastern and Western European countries [43, 44]. Thus, it is important to analyse them in different populations. Therefore, we have formulated a hypothesis that specific dietary patterns can be identified The aim of this study was to describe the dietary patterns in pregnant Polish women and determine the association between dietary factors, pre-pregnancy body mass index, smoking, socio-demographic characteristics and gestational weight gain.

\section{Materials and methods}

\section{Study setting and population}

This cross-sectional study was conducted within 12 months between 2014 and 2015. The data were collected through a self-administered questionnaire and completed with information from the women's medical documentation collected by a trained midwife.

The material consisted of the data of 505 women who, after childbirth, were patients of the Clinic of Obstetrics and Gynaecology of the Provincial Polyclinic Hospital in Kielce, Poland. The women who participated in the study aged 18-42 had given birth to a healthy child (without birth defects) and had labour that occurred after a full-term pregnancy, i.e., after the 37th week of pregnancy. The following patients were excluded from further analysis: four women with twin pregnancies, 18 patients whose labour occurred before the completion of the 37th week, and 25 patients lacking data. Finally, the analysis was conducted on a group of 458 women. This group comprised $12.1 \%$ of all women delivering during the year at the hospital where the study was conducted.

\section{Study measures}

The diet of the study participants during their most recent pregnancy was evaluated with the use of the authors' original semi-quantitative questionnaire of food frequency (FFQ) (Additional file 1). It was based on the principles of adequate nutrition of pregnant women, developed at the Institute of Food and Nutrition in Warsaw [45]. It has been used in previous studies, the results of which have been published in several papers $[7,46,47]$. The questionnaire was completed by all the women at the same time, i.e., 1 day before their scheduled discharge from the hospital. The FFQ assessed the consumption of vegetables (in total), fruit (in total), legumes, meat and meat-based products, sea fish, milk and dairy products, total grain food, whole grains, total fat, sweets and cakes, fast food, total drinks, fruit juice, sugary fizzy drinks, coffee, beer and/or wine, and strong liquors. The questions regarding the intake of particular 
groups of products and drinks during pregnancy concerned the number of standard portions consumed in a day and a week. The size of a portion was determined according to the guidelines defined in the literature [45]. The questionnaire also contained questions related to some eating habits, i.e., the number of meals consumed in a day, snacking between meals, and sweetening with sugar.

The nutritional status of the subjects before pregnancy was assessed on the basis of self-reported data on height and weight before pregnancy, which were used to calculate the BMI. The following groups were distinguished: the underweight group (BMI $<18.5 \mathrm{~kg} / \mathrm{m}^{2} ; N=37$ ), those with a normal body mass $\left(18.5-24.9 \mathrm{~kg} / \mathrm{m}^{2} ; N=377\right)$, and those who were overweight or obese $\left(B M I \geq 25.0 \mathrm{~kg} / \mathrm{m}^{2}\right.$; $N=44$ ). Due to the small number of obese participants $(N=6)$, the analyses were carried out in the combined groups of overweight and obese. The data concerning prenatal body mass and duration of the pregnancy were obtained based on the analysis of medical documentation. The total GWG of each woman was calculated as the difference between their last weight prior to delivery minus their weight before pregnancy. A self-administered questionnaire was used to collect information about age, parity (first, second, third, or subsequent labour), the occurrence of persistent vomiting during the pregnancy (no; yes, in the 1st trimester of pregnancy; or yes, during the whole pregnancy), smoking (never, passive, current smoker or quit smoking after conception), the place of residence (large city: $\geq 50$ thousand residents; small city: $<50$ thousand residents; or countryside), education (lower than secondary school, secondary school, or university), and always having adequate money to buy necessary food (yes or no).

\section{Data analysis}

Factor analysis by principal component analysis was used to determine dietary patterns (DP). Information about the frequency of consumption of certain portions of products included in the FFQ was the basis for the selection of variables for the analysis. The data obtained in this way were transformed into daily food intake and then normalized using the $\mathrm{z}$-score procedure. The Bartlett Test of Sphericity and the Kaiser-Meyer-Olkin Measure of Sampling Adequacy were used to assess data adequacy for factor analysis. The applied procedure excluded sweetening with sugar from the analysis, which did not show any relationship with any other items. Factors were rotated using the Varimax procedure to improve the interpretation of the results. The number of the determined factors was established using Kaiser criterion (>1). Additionally, it was verified by Cattell's criterion (scree plot test). Food items were retained in the pattern if the factor loading value was above 0.30 . On this basis, three factors were determined, and their own values were calculated for each of them. In the dietary pattern analysis, the majority of respondents are in the 'middle'- range of the indicator values and have little characteristic nutritional features, which causes difficulty in interpretation. Therefore we divided these dietary pattern data into quartiles. Study participants were assigned to the factor for which they obtained the highest score (i.e., 4th, the highest quartile).

The total GWG of each woman was calculated as the difference between their last weight prior to delivery minus their weight before pregnancy. GWG was classified as inadequate, adequate, or excessive. Cut-off values of gestational weight gain adequacy were based on the recommendations published by the US Institute of Medicine and were BMI-specific [1]. Adequate weight gain in women who were underweight before pregnancy should be $12.5-18.0 \mathrm{~kg}$; in women with normal body weight it should be $11.5-16.0 \mathrm{~kg}$; and in women who are overweight and obese it should be $7-11.5 \mathrm{~kg}$ and $5-9 \mathrm{~kg}$, respectively. In the three GWG categories, for categorical data (place of residence, level of education, adequate money to buy food, persistent vomiting, smoking, and dietary patterns I-III), the structure indicators were calculated. The chi-square test was calculated for each factor to evaluate the relationships between structure indicators. Distributions of normality were checked for continuous variables (age and BMI of the subjects). The significance of differences between the means in three GWG categories was assessed by means of one factor analysis of variance (ANOVA) or Kruskal-Wallis one-way analysis of variance, depending on the distribution of the characteristics and the homogeneity of the variance. Inter-group differences between the means were evaluated by means of a post-hoc Bonferroni test. To assess the risk of the occurrence of inadequate or excessive GWG, logistic regression analysis was used (OR and 95\% CI). Two models, crude and adjusted, were calculated for both categories of weight gain (inadequate and excessive). Adequate GWG was adopted as the reference level (1.0). The covariates included in the models were age, place of residence, education, having adequate money to buy necessary food, pre-pregnancy BMI, persistent vomiting, smoking, and dietary patterns. The following reference levels were adopted: for place of residence it was large city, for education it was university, for having adequate money to buy necessary food it was the answer "yes", for pre-pregnancy BMI it was normal $\left(18.5-24.9 \mathrm{~kg} / \mathrm{m}^{2}\right)$, for age it was $<30$ years, for persistent vomiting it was the answer "no", for smoking it was never smokers, and for DP it was the lowest quartile (Q1).

Because all of the patients in the group with low GWG marked the same answer category for the variable "having adequate money to buy necessary food", the OR indicator and $95 \% \mathrm{CI}$ were not calculated. The statistical 
analysis was carried out using SPSS software version 16.0. The $p$ values $p<0.05$ were considered statistically significant.

\section{Results}

Table 1 presents the characteristics of the socio-demographic variables and lifestyle of the study participants, depending on the GWG category. The women with excessive GWG were characterized by higher pre-pregnancy BMI compared with women with adequate and inadequate weight gain. Moreover, it was found that excessive GWG was significantly more often related to giving up smoking in the first weeks of pregnancy. Women who continued.

to smoke during pregnancy more often had an inadequate GWG, compared with those who quit smoking. In women with excessive GWG, a lower adherence to prudent patterns was noted in comparison to other participants in the study. Other lifestyle elements and socio-demographic characteristics did not differ in each GWG category.

Three DPs were identified, which, in total, accounted for $33.2 \%$ of the variance (Table 2). These patterns describe mutual associations between consumed food groups, and they were named according to the food groups loading highest on the respective DP. The first one, 'unhealthy', is characterized by high intakes of fast food, alcohol, sugary fizzy drinks, cake, sweets, and coffee. The second pattern, 'varied', is characterized by high intakes of fruit and vegetables, fruit juice, fats, grain products, milk and dairy products, meat and meat-based products, and snacking between meals. The third pattern, 'prudent', was characterized by high consumption of whole grains, vegetables, legumes, sea fish, milk and dairy products and by having meals more often, as well as drinking greater total amounts of liquids; it was negatively correlated with snacking between meals.

In the crude model, the risk of inadequate GWG was significantly higher in women underweight before pregnancy $(\mathrm{OR}=2.14 ; p=0.037$ ) (Table 3). An increased risk of excessive GWG was positively associated with a pre-pregnancy BMI equal to $\geq 25 \mathrm{~kg} / \mathrm{m}^{2}(\mathrm{OR}=6.44 ; p<$ $0.001)$, with giving up smoking $(\mathrm{OR}=9.07 ; p=0.004)$, and with a high score $(\mathrm{Q} 4)$ of varied $\mathrm{DP}(\mathrm{OR}=1.89 ; p=$ 0.036). A lower risk of excessive GWG was associated with being underweight pre-pregnancy compared with having normal body mass $(\mathrm{OR}=0.17 ; p=0.020)$ and a high adherence $(\mathrm{Q} 4)$ to prudent $\mathrm{DP}(\mathrm{OR}=0.047$; $p=0.016$ ).

In the adjusted model, the factor increasing the risk of inadequate GWG was being underweight pre-pregnancy $(\mathrm{OR}=2.61 ; p=0.018)$, whereas this risk was significantly lower in the third or subsequent pregnancy compared with the first one $(\mathrm{OR}=0.39 ; p=0.042)$ (Table 4). The factors increasing the risk of excessive GWG were being overweight or obese pre-pregnancy $(\mathrm{OR}=7.00 ; p=$ 0.031 ) and giving up smoking in the first weeks of pregnancy ( $\mathrm{OR}=7.32 ; p=0.019)$ (Table 4$)$; however, the risk of excessive GWG was decreased by being underweight pre-pregnancy $(\mathrm{OR}=0.20 ; p=0.041)$, being the third or subsequent pregnancy compared to the first $(\mathrm{OR}=0.37$; $p=0.018)$ and with having high adherence $(\mathrm{Q} 4)$ to the prudent $\mathrm{DP}(\mathrm{OR}=0.47 ; p=0.033)$.

\section{Discussion}

To the best of our knowledge, this is the first paper to identify the DP of pregnant women in Poland. In women in the highest quartile of the 'prudent' pattern, characterized by high intakes of whole grains, vegetables, legumes, sea fish, milk and dairy products, and avoiding snacking between meals, the risk of excessive GWG was significantly lower. Dietary patterns, as is well known, can differ between countries and populations, which accounts for the fact that the results obtained are not always comparable with the results of studies by other authors. Lai et al. found that the highest tertile of plant-based protein food intake was associated with a $60 \%$ lower likelihood of inadequate GWG and a 34\% lower likelihood of excessive GWG [48]. Stuebe et al. [49] showed that a vegetarian diet in the first trimester is inversely associated with excessive GWG. Studies conducted in Norway showed that adherence to a regional diet rich in fruits and vegetables, potatoes, whole grains, fish, game, milk, and drinking water during pregnancy may facilitate the maintenance of optimal GWG in normal-weight women [50]. Tielemans et al. found that specific DP can play a significant role in early pregnancy but is not subsequently related to GWG [35]. However, these authors noted more moderate GWG in normalweight women with higher scores on the 'nuts, high-fibre cereals, and soy' pattern than in women with a low score for this pattern. Wrottesley et al. noted that an increased intake of a traditional diet pattern high in whole grains, vegetables, legumes, traditional meats, and of a decreased intake of sugar and fat was related to a lower risk of excessive GWG [51]. Chuang et al. confirmed that appropriate GWG was related to intentional planning of meals and snacks [52]. Additionally, the results of intervention studies quite explicitly show that rationale eating habits among pregnant women contributes to the optimization of their GWG $[29,36,53]$.

Several authors have shown that an unhealthy DP is significantly correlated with excessive GWG $[49,51,54]$, although our study did not confirm such a relationship. Unambiguous scores related to the abovementioned associations may have occurred because dietary patterns vary according to age, ethnicity, culture, and other lifestyle factors. In a study conducted among Swedish 
Table 1 The characteristics of the study participants in three categories of GWG (N\%; X \pm SD)

\begin{tabular}{|c|c|c|c|c|}
\hline \multirow[t]{2}{*}{ Variables } & \multicolumn{3}{|l|}{ Gestational weight gain } & \multirow[t]{2}{*}{$p$ value } \\
\hline & $\begin{array}{l}\text { Inadequate }(N=100) \\
9.49 \pm 2.01 \mathrm{~kg}\end{array}$ & $\begin{array}{l}\text { Adequate }(N=207) \\
13.76 \pm 1.66 \mathrm{~kg}\end{array}$ & $\begin{array}{l}\text { Excessive }(N=151) \\
19.60 \pm 4.04 \mathrm{~kg}\end{array}$ & \\
\hline Age $(X \pm S D)$ & $29.19 \pm 4.87$ & $29.62 \pm 4.93$ & $30.43 \pm 3.80$ & $0.090^{\mathrm{A}}$ \\
\hline Pre-pregnancy BMI $(X \pm S D)$ & $20.92 \pm 2.46$ & $21.32 \pm 2.50$ & $22.82 \pm 3.57^{\mathrm{a}, \mathrm{b}}$ & $<0.001^{A}$ \\
\hline \multicolumn{5}{|l|}{ Place of residence } \\
\hline village & $33(33.0)$ & 80 (38.6) & $61(40.4)$ & \multirow[t]{3}{*}{$0.700^{c}$} \\
\hline town & $19(19.0)$ & $42(20.3)$ & $31(20.5)$ & \\
\hline city & $48(48.0)$ & $85(41.1)$ & $59(39.1)$ & \\
\hline \multicolumn{5}{|l|}{ Education } \\
\hline lower than secondary school & $6(6.0)$ & $10(4.8)$ & $12(7.9)$ & \multirow[t]{3}{*}{$0.729^{C}$} \\
\hline secondary school & $30(30.0)$ & $55(26.6)$ & $39(25.8)$ & \\
\hline university & $64(64.0)$ & $142(68.6)$ & $100(66.2)$ & \\
\hline \multicolumn{3}{|l|}{ Having adequate money to buy necessary food } & 1 & \\
\hline yes & $100(100.0)$ & $202(97.6)$ & $47(98.0)$ & \multirow[t]{2}{*}{$0.306^{\mathrm{C}}$} \\
\hline no & $0(0.0)$ & $5(2.4)$ & $3(2.0)$ & \\
\hline \multicolumn{5}{|l|}{ Smoking } \\
\hline non-smokers & $55(55.0)$ & $120(58.0)$ & $86(57.0)$ & \multirow[t]{4}{*}{$0.003^{C}$} \\
\hline passive smokers & $28(28.0)$ & $65(31.4)$ & $42(27.8)$ & \\
\hline current smokers & $15(15.0)$ & $20(9.7)$ & $10(6.6)$ & \\
\hline women who quit smoking after conception & $2(2.0)$ & $2(1.0)$ & $13(8.6)$ & \\
\hline \multicolumn{5}{|l|}{ Persistent vomiting } \\
\hline no & $60(60.0)$ & $119(57.5)$ & $98(65.3)$ & \multirow[t]{3}{*}{$0.411^{c}$} \\
\hline yes, in the 1st trimester of pregnancy & $36(36.0)$ & $75(36.2)$ & $48(32.0)$ & \\
\hline yes, during the whole pregnancy & $4(4.0)$ & $13(6.3)$ & $4(2.7)$ & \\
\hline \multicolumn{5}{|l|}{ Parity } \\
\hline first & $54(54.0)$ & $102(49.3)$ & $80(51.5)$ & \multirow[t]{3}{*}{$0.243^{C}$} \\
\hline second & $36(36.0)$ & 69 (33.3) & $56(37.1)$ & \\
\hline third or subsequent labour & $10(10.0)$ & $36(17.4)$ & $15(9.9)$ & \\
\hline \multicolumn{5}{|l|}{ Unhealthy DP } \\
\hline Q1 & $21(21.0)$ & $52(25.1)$ & $42(27.8)$ & \multirow[t]{4}{*}{$0.715^{c}$} \\
\hline Q2 & $27(27.0)$ & $57(27.5)$ & $32(21.2)$ & \\
\hline Q3 & $28(28.0)$ & $46(22.2)$ & $39(25.8)$ & \\
\hline Q4 & $24(24.0)$ & $52(25.1)$ & $38(25.2)$ & \\
\hline \multicolumn{5}{|l|}{ Varied DP } \\
\hline Q1 & $26(26.0)$ & $59(28.5)$ & $30(19.9)$ & \multirow[t]{4}{*}{$0.246^{c}$} \\
\hline Q2 & $30(30.0)$ & $50(24.2)$ & 35 (23.2) & \\
\hline Q3 & $25(25.0)$ & 49 (23.7) & $39(25.8)$ & \\
\hline Q4 & 19 (19.0) & $49(23.7)$ & $47(31.1)$ & \\
\hline \multicolumn{5}{|l|}{ Prudent DP } \\
\hline Q1 & $20(20.0)$ & 47 (22.7) & 48 (31.8) & \multirow[t]{4}{*}{$0.036^{C}$} \\
\hline Q2 & $30(30.0)$ & $47(22.7)$ & $39(25.8)$ & \\
\hline Q3 & $18(18.0)$ & $57(27.5)$ & $37(24.5)$ & \\
\hline Q4 & $32(32.0)$ & $56(27.1)$ & $27(17.9)$ & \\
\hline
\end{tabular}

Q represents quartile; DP represents dietary pattern; ${ }^{\mathrm{A}}$ represents one-way ANOVA; and ${ }^{\mathrm{C}}$ represents the chi-square test. The numbers in bold indicate statistically significant results; ${ }^{\mathrm{a}}$ represents the Bonferroni post hoc test $p<0.001$ (adequate-excessive; and ${ }^{\mathrm{b}}$ represents the Bonferroni post hoc test $\mathrm{p}<0.001$ (inadequate-excessive) 
Table 2 Factor-loading matrix for major dietary patterns*

\begin{tabular}{llll}
\hline Food groups & $\begin{array}{l}\text { Factor I } \\
\text { Unhealthy }\end{array}$ & $\begin{array}{l}\text { Factor II } \\
\text { Varied }\end{array}$ & $\begin{array}{l}\text { Factor III } \\
\text { Prudent }\end{array}$ \\
\hline Fast food & 0.682 & & \\
Beer or wine & 0.682 & & \\
Strong liquors & 0.600 & & \\
Sugary fizzy drinks & 0.652 & & \\
Sweets, cakes & 0.487 & & \\
Coffee & 0.410 & & \\
Fruit & & 0.661 & \\
Fat in total & & 0.612 & \\
Cereals in total & & 0.556 & \\
Snacking between meals & & 0.468 & -0.412 \\
Vegetables & & 0.443 & 0.421 \\
Milk and dairy products & & 0.363 & 0.355 \\
Fruit juice & & 0.330 & \\
Meat and meat-based products & & 0.300 & \\
Whole grains & & & 0.710 \\
Number of meals a day & & & 0.502 \\
Legumes & & & 0.497 \\
Sea fish & & & 0.382 \\
Drinks in total & & \\
Percentage of variance & & \\
explained (\%) & & & \\
\hline
\end{tabular}

*Values $<0.30$ were excluded for simplicity

women, their intakes of caloric beverages, snacks, fish, and bread were positively related to excessive GWG [30]. Uusatilo et al. found that greater adherence to a 'fast food' DP, characterized by high intakes of fast food items such as hamburgers and pizza, as well as sweets, soft drinks and added sugar, was positively associated with GWG [54].

The results of our study showed that the factors related to inadequate GWG were pre-pregnancy BMI, smoking and parity. Being underweight pre-pregnancy was significantly correlated with gaining too little weight compared to gaining weight within the guidelines. It is commonly emphasized that being underweight results in a higher risk of insufficient GWG, whereas being overweight and/or obese at the time of conception is related to a higher risk of excessive gain $[1,6,27,30]$. Fontaine et al. showed that 33 to $50 \%$ of healthy weight women and 50 to $75 \%$ of overweight and obese women had excessive GWG [55]. Heerman et al. found excessive GWG in 55.0\% of mothers who were overweight before pregnancy, in $43.7 \%$ of those who were obese, and only in $37.5 \%$ of mothers who were underweight before pregnancy [56]. The results of our analyses agree with those of other authors.
The factor that strongly determined GWG in our study was quitting smoking. The results of several other papers also confirmed that women who quit smoking after conception gain much more weight than women who had never smoked [57-59]. Research carried out in the general population suggests, that heavy smokers ( $\geq 25$ cigarettes per day) and those who were obese before quitting gain the most weight [60]. Although quitting smoking is a significant health-promoting change in lifestyle, it can also lead to negative metabolic consequences. Bush et al., on the basis of a literature review, found that weight gain related to quitting smoking results mainly from a decline in resting-state basal metabolism [61]. Furthermore, nicotine in cigarettes is an appetite suppressant. Depriving oneself of it results in an increase in appetite and in emotional eating, calorie misperception, and a greater craving for sweets, which may lead to excessive calorie intake.

The results of our study are consistent with reports of other authors that primiparous women gain more weight and that the probability of the occurrence of excessive GWG is higher compared to their multiparous counterparts [36, 62]. Only Hill et al. did not find any differences in GWG between primiparous and multiparous women [63]. In several papers, there were no significant associations reported between age and GWG [64-66], which is in agreement with the results of our study. In other studies, it is emphasized that a lower GWG is present in older women [1,36, 67]. However, the results obtained by these authors usually concern women aged up to $>35$ and not $\geq 30$, as is the case in our analysis.

Despite the large number of publications regarding the association between socioeconomic status and GWG, the literature is inconsistent $[32,33,39-41,68,69]$. Women with low income have an increased risk for both excessive and inadequate GWG [69]. The reason for this is largely due to a lack of understanding of the importance of a healthy diet during pregnancy as well as limited access to healthy food. However, Guilloty et al. found that socio-demographic characteristics were not associated with GWG, which is consistent with the results of our studies [70]. Among the participants in our study, there were few women (only 1.75\%) who reported a lack of adequate money to buy necessary food. Therefore, the results obtained should be considered with great caution. In most studies, a higher risk of gaining weight outside of the recommendations was found in women with a lower level of education [32, 40, 71, 72]. Cohen et al. suggested that higher education plays a role in healthier GWG for some, but not all, groups of pregnant women [33]. In most cases, higher education was associated with a lower chance of inadequate GWG. Educational attainment was also associated with excessive GWG; however, ethnicity and pre-pregnancy 
Table 3 Factors determining the risk of inadequate and excessive GWG (unadjusted)

\begin{tabular}{|c|c|c|c|}
\hline \multirow[t]{2}{*}{ Variables } & \multicolumn{3}{|c|}{ Gestational weight gain } \\
\hline & $\begin{array}{l}\text { Inadequate } \\
(N=100)\end{array}$ & $\begin{array}{l}\text { Adequate } \\
(N=207)\end{array}$ & $\begin{array}{l}\text { Excessive } \\
(N=151)\end{array}$ \\
\hline \multicolumn{4}{|l|}{ Age } \\
\hline$<30$ years & 1.0 & & 1.0 \\
\hline$\geq 30$ years & $1.02(0.63-1.64)$ & 1.0 & $1.36(0.89-2.08$ \\
\hline$p$ value & 0.940 & & 0.159 \\
\hline \multicolumn{4}{|l|}{ Pre-pregnancy BMI } \\
\hline$<18.5 \mathrm{~kg} / \mathrm{m}^{2}$ & $2.14(1.05-4.36)$ & 1.0 & $\mathbf{0 . 1 7}(0.04-0.7$ \\
\hline$p$ value & 0.037 & & 0.020 \\
\hline $18.5-24.9 \mathrm{~kg} / \mathrm{m}^{2}$ & 1.0 & & 1.0 \\
\hline$\geq 25.0 \mathrm{~kg} / \mathrm{m}^{2}$ & $0.85(0.22-3.28)$ & 1.0 & $6.44(2.87-14$. \\
\hline$p$ value & 0.812 & & $<0.001$ \\
\hline \multicolumn{4}{|l|}{ Place of residence } \\
\hline city & 1.0 & & 1.0 \\
\hline town & $0.80(0.42-1.53)$ & 1.0 & $1.06(0.60-1.88$ \\
\hline$p$ value & 0.502 & & 0.833 \\
\hline village & $0.73(0.43-1.25)$ & 1.0 & $1.10(0.69-1.76$ \\
\hline$p$ value & 0.253 & & 0.695 \\
\hline \multicolumn{4}{|l|}{ Education } \\
\hline \multicolumn{4}{|l|}{ university } \\
\hline secondary school & $1.21(0.71-2.06)$ & 1.0 & $1.01(0.62-1.63$ \\
\hline$p$ value & 0.484 & & 0.978 \\
\hline lower & $1.33(0.46-3.82)$ & 1.0 & $1.70(0.71-4.10$ \\
\hline$p$ value & 0.595 & & 0.234 \\
\hline
\end{tabular}

Having adequate money to buy necessary food

$\begin{array}{llll}\text { yes } & 1.0 & & 1.0 \\ \text { no } & -^{*} & 1.0 & 0.82(0.19-3.51) \\ p \text { value } & - & & 0.794\end{array}$

Smoking

\begin{tabular}{|c|c|c|c|}
\hline non-smokers & 1.0 & & 1.0 \\
\hline passive smokers & $0.94(0.54-1.62)$ & 1.0 & $0.90(0.56-1.45)$ \\
\hline$p$ value & 0.824 & & 0.670 \\
\hline current smokers & $1.64(0.78-3.44)$ & 1.0 & $0.70(0.31-1.57)$ \\
\hline$p$ value & 0.193 & & 0.383 \\
\hline $\begin{array}{l}\text { women who quit } \\
\text { smoking after } \\
\text { conception }\end{array}$ & $2.18(0.30-15.89)$ & 1.0 & $9.07(1.20-41.23)$ \\
\hline$p$ value & 0.441 & & 0.004 \\
\hline \multicolumn{4}{|l|}{ ersistent vomiting } \\
\hline no & 1.0 & & 1.0 \\
\hline $\begin{array}{l}\text { yes, in the 1st } \\
\text { trimester of } \\
\text { pregnancy }\end{array}$ & $0.95(0.58-1.58)$ & 1.0 & $0.78(0.50-1.22)$ \\
\hline$p$ value & 0.848 & & 0.272 \\
\hline yes, during the & $0.61(0.19-1.95)$ & 1.0 & $0.37(0.12-1.18)$ \\
\hline
\end{tabular}

Table 3 Factors determining the risk of inadequate and excessive GWG (unadjusted) (Continued)

\begin{tabular}{|c|c|c|c|}
\hline \multirow[t]{2}{*}{ Variables } & \multicolumn{3}{|c|}{ Gestational weight gain } \\
\hline & $\begin{array}{l}\text { Inadequate } \\
(N=100)\end{array}$ & $\begin{array}{l}\text { Adequate } \\
(N=207)\end{array}$ & $\begin{array}{l}\text { Excessive } \\
(N=151)\end{array}$ \\
\hline \multicolumn{4}{|l|}{ whole pregnancy } \\
\hline$p$ value & 0.405 & & 0.094 \\
\hline \multicolumn{4}{|l|}{ Parity } \\
\hline first & 1.0 & & 1.0 \\
\hline second & $0.99(0.59-1.66)$ & 1.0 & $1.03(0.65-1.64)$ \\
\hline$p$ value & 0.956 & & 0.884 \\
\hline $\begin{array}{l}\text { third or subsequent } \\
\text { labour }\end{array}$ & $0.49(0.20-1.20)$ & 1.0 & $0.61(0.30-1.27)$ \\
\hline$p$ value & 0.118 & & 0.186 \\
\hline \multicolumn{4}{|l|}{ Unhealthy DP } \\
\hline Q1 & 1.0 & & 1.0 \\
\hline $\mathrm{Q}_{2}$ & $1.17(0.59-2.32)$ & 1.0 & $0.69(0.38-1.26)$ \\
\hline$p$ value & 0.647 & & 0.230 \\
\hline $\mathrm{Q}_{3}$ & $1.51(0.75-3.01)$ & 1.0 & $1.05(0.58-1.89)$ \\
\hline$p$ value & 0.245 & & 0.872 \\
\hline $\mathrm{Q}_{4}$ & $1.14(0.57-2.30)$ & 1.0 & $0.91(0.51-1.62)$ \\
\hline$p$ value & 0.709 & & 0.737 \\
\hline \multicolumn{4}{|l|}{ Varied DP } \\
\hline Q1 & 1.0 & & 1.0 \\
\hline $\mathrm{Q}_{2}$ & $1.36(0.71-2.60)$ & 1.0 & $1.38(0.74-2.55)$ \\
\hline$p$ value & 0.349 & & 0.309 \\
\hline $\mathrm{Q}_{3}$ & $1.16(0.59-2.26)$ & 1.0 & $1.57(0.85-2.88)$ \\
\hline$p$ value & 0.667 & & 0.149 \\
\hline $\mathrm{Q}_{4}$ & $0.88(0.44-1.78)$ & 1.0 & $1.89(1.04-3.42)$ \\
\hline$p$ value & 0.721 & & 0.036 \\
\hline \multicolumn{4}{|l|}{ Prudent DP } \\
\hline Q1 & 1.0 & & 1.0 \\
\hline $\mathrm{Q}_{2}$ & $1.50(0.75-3.01)$ & 1.0 & $0.81(0.45-1.46)$ \\
\hline$p$ value & 0.253 & & 0.486 \\
\hline $\mathrm{Q}_{3}$ & $0.74(0.35-1.56)$ & 1.0 & $0.64(0.36-1.13)$ \\
\hline$p$ value & 0.432 & & 0.124 \\
\hline $\mathrm{Q}_{4}$ & $1.34(0.68-2.65)$ & 1.0 & $\mathbf{0 . 4 7}(0.26-0.87)$ \\
\hline$p$ value & 0.396 & & 0.016 \\
\hline
\end{tabular}

The numbers in bold indicate statistically significant results; DP represents dietary pattern; Q represents quartile; * represents the number of individuals in the category 'having adequate money to buy necessary food, answer no', and the reference group is "adequate" GWG

overweight status both modified this association, sometimes in different directions. In addition, the correlation analysis among the participants in our study suggests that a high adherence to the unhealthy DP negatively correlated with a higher level of education (Spearman's rank correlation coefficient $=-0.28 ; p<0.05$; data not shown). Thus, although there is no direct relationship 
Table 4 Factors determining the risk of inadequate and excessive GWG (adjusted)

\begin{tabular}{|c|c|c|c|}
\hline \multirow[t]{2}{*}{ Variables } & \multicolumn{3}{|c|}{ Gestational weight gain } \\
\hline & $\begin{array}{l}\text { Inadequate } \\
(N=100)\end{array}$ & $\begin{array}{l}\text { Adequate } \\
(N=207)\end{array}$ & $\begin{array}{l}\text { Excessive } \\
(N=151)\end{array}$ \\
\hline \multicolumn{4}{|l|}{ Age } \\
\hline$<30$ years & 1.0 & & 1.0 \\
\hline$\geq 30$ years & $1.30(0.70-2.44)$ & 1.0 & $1.67(0.97-2.88)$ \\
\hline$p$ value & 0.410 & & 0.065 \\
\hline \multicolumn{4}{|l|}{ Pre-pregnancy BMI } \\
\hline$<18.5 \mathrm{~kg} / \mathrm{m}^{2}$ & $2.61(1.17-5.78)$ & 1.0 & $0.20(0.04-0.94)$ \\
\hline$p$ value & 0.018 & & 0.041 \\
\hline $18.5-24.9 \mathrm{~kg} / \mathrm{m}^{2}$ & 1.0 & & 1.0 \\
\hline$\geq 25.0 \mathrm{~kg} / \mathrm{m}^{2}$ & $0.88(0.21-3.73)$ & 1.0 & $7.00(2.87-17.08)$ \\
\hline$p$ value & 0.872 & & $<0.001$ \\
\hline \multicolumn{4}{|l|}{ Place of residence } \\
\hline city & 1.0 & & 1.0 \\
\hline town & $0.70(0.34-1.44)$ & 1.0 & $1.27(0.65-2.49)$ \\
\hline$p$ value & 0.330 & & 0.488 \\
\hline village & $0.68(0.36-1.29)$ & 1.0 & $1.13(0.62-2.08)$ \\
\hline$p$ value & 0.240 & & 0.689 \\
\hline \multicolumn{4}{|l|}{ Education } \\
\hline university & 1.0 & & 1.0 \\
\hline secondary school & $1.41(0.75-2.65)$ & 1.0 & $0.86(0.46-1.59)$ \\
\hline$p$ value & 0.289 & & 0.627 \\
\hline lower & $1.82(0.52-6.42)$ & 1.0 & $1.70(0.54-5.39)$ \\
\hline$p$ value & 0.350 & & 0.365 \\
\hline \multicolumn{4}{|c|}{ Having adequate money to buy necessary food } \\
\hline yes & 1.0 & & 1.0 \\
\hline no & $-*$ & 1.0 & $1.09(0.20-6.04)$ \\
\hline$p$ value & - & & 0.924 \\
\hline \multicolumn{4}{|l|}{ Smoking } \\
\hline non-smokers & 1.0 & & 1.0 \\
\hline passive smokers & $0.88(0.47-1.63)$ & 1.0 & $0.96(0.54-1.70)$ \\
\hline$p$ value & 0.683 & & 0.879 \\
\hline current smokers & $1.64(0.64-4.20)$ & 1.0 & $1.08(0.39-2.98)$ \\
\hline$p$ value & 0.305 & & 0.878 \\
\hline $\begin{array}{l}\text { women who quit } \\
\text { smoking after } \\
\text { conception }\end{array}$ & $2.08(0.24-18.02)$ & 1.0 & $7.32(1.39-38.56)$ \\
\hline$p$ value & 0.506 & & 0.019 \\
\hline \multicolumn{4}{|l|}{ Persistent vomiting } \\
\hline no & 1.0 & & 1.0 \\
\hline $\begin{array}{l}\text { yes, in the 1st } \\
\text { trimester of } \\
\text { pregnancy }\end{array}$ & $0.90(0.51-1.60)$ & 1.0 & $0.63(0.37-1.08)$ \\
\hline$p$ value & 0.732 & & 0.094 \\
\hline $\begin{array}{l}\text { yes, during the } \\
\text { whole pregnancy }\end{array}$ & $0.48(0.13-1.79)$ & 1.0 & $0.44(0.12-1.60)$ \\
\hline$p$ value & 0.276 & & 0.214 \\
\hline \multicolumn{4}{|l|}{ Parity } \\
\hline first & 1.0 & & 1.0 \\
\hline
\end{tabular}

Table 4 Factors determining the risk of inadequate and excessive GWG (adjusted) (Continued)

\begin{tabular}{|c|c|c|c|}
\hline \multirow[t]{2}{*}{ Variables } & \multicolumn{3}{|c|}{ Gestational weight gain } \\
\hline & $\begin{array}{l}\text { Inadequate } \\
(N=100)\end{array}$ & $\begin{array}{l}\text { Adequate } \\
(N=207)\end{array}$ & $\begin{array}{l}\text { Excessive } \\
(N=151)\end{array}$ \\
\hline second & $0.91(0.47-1.77)$ & 1.0 & $0.74(0.42-1.29)$ \\
\hline$p$ value & 0.789 & & 0.289 \\
\hline $\begin{array}{l}\text { third or subsequent } \\
\text { labour }\end{array}$ & $0.39(0.16-0.96)$ & 1.0 & $\mathbf{0 . 3 7}(0.16-0.84)$ \\
\hline$p$ value & 0.042 & & 0.018 \\
\hline \multicolumn{4}{|l|}{ Unhealthy DP } \\
\hline Q1 & 1.0 & & 1.0 \\
\hline $\mathrm{Q}_{2}$ & $1.43(0.68-3.00)$ & 1.0 & $0.62(0.26-1.04)$ \\
\hline$p$ value & 0.342 & & 0.066 \\
\hline $\mathrm{Q}_{3}$ & $1.45(0.65-3.21)$ & 1.0 & $0.97(0.49-1.95)$ \\
\hline$p$ value & 0.362 & & 0.942 \\
\hline $\mathrm{Q}_{4}$ & $1.15(0.49-2.71)$ & 1.0 & $1.00(0.48-2.08)$ \\
\hline$p$ value & 0.754 & & 0.996 \\
\hline \multicolumn{4}{|l|}{ Varied DP } \\
\hline Q1 & 1.0 & & 1.0 \\
\hline $\mathrm{Q}_{2}$ & $1.53(0.76-3.09)$ & 1.0 & $1.41(0.70-2.85)$ \\
\hline$p$ value & 0.234 & & 0.332 \\
\hline $\mathrm{Q}_{3}$ & $1.04(0.49-2.21)$ & 1.0 & $1.38(0.69-2.78)$ \\
\hline$p$ value & 0.916 & & 0.367 \\
\hline $\mathrm{Q}_{4}$ & $0.83(0.36-1.80)$ & 1.0 & $1.85(0.92-2.78)$ \\
\hline$p$ value & 0.640 & & 0.085 \\
\hline \multicolumn{4}{|l|}{ Prudent DP } \\
\hline Q1 & 1.0 & & 1.0 \\
\hline $\mathrm{Q}_{2}$ & $1.27(0.60-2.69)$ & 1.0 & $0.70(0.35-1.39)$ \\
\hline$p$ value & 0.532 & & 0.301 \\
\hline $\mathrm{Q}_{3}$ & $0.62(0.28-1.39)$ & 1.0 & $0.72(0.38-1.39)$ \\
\hline$p$ value & 0.247 & & 0.329 \\
\hline $\mathrm{Q}_{4}$ & $1.38(0.66-2.91)$ & 1.0 & $\mathbf{0 . 4 7}(0.23-0.97)$ \\
\hline$p$ value & 0.394 & & 0.033 \\
\hline
\end{tabular}

The numbers in bold indicate statistically significant results, DP represents dietary pattern, $\mathrm{Q}$ represents quartile, * represents the number of individuals in the category "having adequate money to buy necessary food, answer "no", and the reference group is "adequate" GWG

between education and GWG, this factor may affect the GWG indirectly by modifying the diet. This issue requires confirmation with a larger group of women.

The main limitation of the study is the lack of data concerning the physical activity of the women subjects, which can have an influence on GWG [27, 29]. However, some of the studies did not confirm any significant associations between physical activity and GWG [36, 37]. Moreover, for the evaluation of food intake, a nonvalidated, authors' original semi-quantitative questionnaire was applied. Standard questionnaires are very long and extensive, and in the opinion of the management of the hospital, they could be an excessive burden for women shortly after delivery. They could also contribute to lower 
response rates among women. The results obtained should also be treated with caution because of the small number of obese participants $(N=6 ; 1.31 \%)$, as well as the small number of those who were overweight $(N=38$; $8.30 \%)$. However, it is known that in the Polish population, excessive body mass occurs least often among young women. In a representative group (i.e., 1129 female university students aged 20-24 years from the south of Poland), it was noted that $6.5 \%$ were overweight and only $0.5 \%$ were obese (BMI was calculated on the basis of the measurements of body height and mass) [73]. There was also a small number of women who quit smoking during pregnancy $(N=17 ; 3.7 \%)$. Therefore, the smoking results should also be approached with great caution.

\section{Conclusions}

Three dietary patterns, characteristic of pregnant women in Poland, were identified: 'unhealthy', 'varied' and 'prudent'. The risk of excessive GWG was lower in women with a high adherence to the prudent DP, which was characterized by a high intake of vegetables, legumes, whole grains, sea fish, milk, and dairy products, as well as a larger amount of total drinks, the consumption of a larger number of planned meals, and avoiding snacking between meals. The factors that was positively associated with a higher risk of excessive GWG in the study population were quitting smoking at the beginning of pregnancy and excessive body mass at the time of conception. The risk of inappropriate GWG (both too low and excessive) was smaller in the third and subsequent pregnancies compared to the first. Being underweight pre-pregnancy increased the risk of inadequate GWG and decreased the risk of excessive weight gain. Women who were overweight or obese pre-pregnancy and those who quit smoking at the beginning of pregnancy should be provided dietary guidance to prevent them from excessive GWG. Prevention programmes for pregnant women, developed to optimize their GWG, should include socio-economic factors, cultural traditions, and dietary patterns that are specific to a given population.

\section{Additional file}

Additional file 1: The Food Frequency Questionnaire (FFQ). The authors' original semi-quantitative questionnaire of food frequency consumption during the most recent pregnancy. (DOCX $21 \mathrm{~kb}$ )

\section{Abbreviations}

BMI: Body mass index; DP: Dietary pattern; FFQ: Food frequency questionnaire: GWG: Gestational weight gain; IOM: Institute of medicine; OR: Odds Ratio; Q: Quartile; US: United States of America

\section{Acknowledgements}

The study was conducted with the support of the Regional Polyclinic Hospital in Kielce. The authors would like to thank AJE (http://www.aje.cn/) for the English language review.

\section{Funding}

The study was supported by The Ministry of Science and Higher Education from the funds received within the statutory financing activity for the Faculty of Medicine and Health Sciences, Jan Kochanowski University, research project No. 615507.00. The funding body was not involved in the study design; collection, analysis, or interpretation of data; or manuscript writing.

\section{Availability of data and materials}

The paper copies of the completed questionnaires were deposited in the archives of the Faculty of Medicine and Health Sciences of Jan Kochanowski University. The electronic version of the data has been coded and is protected by a password on a hard-drive, which only the main researcher has access to. The datasets used and/or analysed during the current study are available from the corresponding author on reasonable request.

\section{Author's contributions}

ES conceptualized the project, participated in the statistical analysis, and wrote the manuscript. WR provided clinical expert oversight to the gynaecologic components of the survey development and analysis. OAG and GP carried out survey development and recruitment and are involved in analysis and interpretation of data and drafting the manuscript. EC participated in the statistical analysis and reviewed the manuscript. SG reviewed the manuscript and revised it critically for important intellectual content. All authors read and approved the final version of the manuscript.

\section{Ethics approval and consent to participate}

The study was approved by the Bioethical Commission of the Faculty of Medicine and Health Sciences of the Jan Kochanowski University in Kielce, operating in accordance with the principles of Good Clinical Practice (opinion number: 6/2014). The participants were informed in detail about the purpose and manner of the research, as well as the right to withdraw from the study at any time. All participants gave their written consent to participate in the study.

\section{Consent for publication}

Not applicable.

\section{Competing interests}

The authors declare that they have no competing interest.

\section{Publisher's Note}

Springer Nature remains neutral with regard to jurisdictional claims in published maps and institutional affiliations.

\section{Author details}

${ }^{1}$ Department of Nutrition and Dietetics, Faculty of Medicine and Health Sciences, Jan Kochanowski University, Kielce, Poland. ${ }^{2}$ Department of Gynecological and Obstetric Prophylaxis, Faculty of Medicine and Health Sciences, Jan Kochanowski University, Kielce, Poland. ${ }^{3}$ Clinic of Neonatology at the Regional Polyclinic Hospital, Kielce, Poland. ${ }^{4}$ Department of Developmental Age Research, Faculty of Medicine and Health Sciences, Jan Kochanowski University, Kielce, Poland. ${ }^{5}$ Department of Surgery and Surgical Nursing with the Scientific Research Laboratory, Faculty of Medicine and Health Sciences, Jan Kochanowski University, Kielce, Poland.

Received: 27 March 2018 Accepted: 22 November 2018

Published online: 03 December 2018

References

1. Rasmussen KM, Pregnancy YALWGD. Reexamining the guidelines. Institute of Medicine. Washington D.C: National Research Council of the National Academies; 2009.

2. Branum AM, Sharma AJ, Deputy NP. Gestational weight gain among women with full-term, singleton births, compared with recommendations - 48 states and the District of Columbia, 2015. Morb Mortal Wkly Rep. 2016;65:1121.

3. Power ML, Lott ML, Mackeen A, AD DBJ, Schulkin J. A retrospective study of gestational weight gain in relation to the Institute of Medicine's recommendations by maternal body mass index in rural Pennsylvania from 2006 to 2015. BMC Pregnancy \& Childbirth. 2018;18:239.

4. Alberico S, Montico M, Barresi V, Monasta L, Businelli C, Soini V et al. The role of gestational diabetes, pre-pregnancy body mass index and 
gestational weight gain on the risk of newborn macrosomia: results from a prospective multicentre study. BMC Pregnancy Childbirth. 2014;14:23.

5. Beyerlein A, Nehring I, Rzehak P, Heinrich J, Müller MJ, et al. Gestational weight gain and body mass index in children: results from three German cohort studies. PLoS One. 2012;7:e33205.

6. Wierzejska R, Jarosz M, Stelmachów J, Sawicki W, Siuba M. Gestational weight gain by pre-pregnancy BMI. Postępy Nauk Med. 2011;9:718-23.

7. Suliga E, Adamczyk-Gruszka OK. Health behaviours of pregnant women and gestational weight gains - a pilot study. Med Stud./Studia Medyczne. 2015; 31:161-7.

8. Rong K, Yu K, Han X, Szeto IM, Qin X, Wang J, et al. Pre-pregnancy BMI, gestational weight gain and postpartum weight retention: a meta-analysis of observational studies. Public Health Nutr. 2015;18:2172-82.

9. Goldstein RF, Abell SK, Ranashina S, Misso M, Boyle JA, Black MH, et al. Association of gestational weight gain with maternal and infant outcomes: a systematic review and meta-analysis. JAMA. 2017;317: 2207-25.

10. de Boo HA, Harding JE. The developmental origins of adult disease (barker) hypothesis. Aust N Z J Obstet Gynaecol. 2006;46:4-14.

11. Contreras ZA, Ritz B, Virk J, Cockburn M, Heck JE. Maternal pre-pregnancy and gestational diabetes, obesity, gestational weight gain, and risk of cancer in young children: a population-based study in California. Cancer Causes Control. 2016:27:1273-85.

12. Mourtakos SP, Tambalis KD, Panagiotakos DB, Antonogeorgos G, Alexis CD, Georgoulis M, et al. Association between gestational weight gain and risk of obesity in preadolescence: a longitudinal study (1997-2007) of 5125 children in Greece. J Hum Nutr Diet. 2017;30:51-8.

13. Freitas-Vilela AA, Pearson RM, Emmett P, Heron J, Smith ADAC, Emond A, et al. Maternal dietary patterns during pregnancy and intelligence quotients in the offspring at 8 years of age: findings from the ALSPAC cohort. Matern Child Nutr. 2018;14. https://doi.org/10.1111/mcn.12431.

14. Nehring I, Schmoll S, Beyerlein A, Hauner H, von Kries R. Gestational weight gain and long-term postpartum weight retention: a meta-analysis. Am J Clin Nutr. 2011;94:1225-31.

15. Mannan MS, Doi A, Mamun AA. Association between weight gain during pregnancy and postpartum weight retention and obesity: a bias-adjusted meta-analysis. Nutr Rev. 2013;71:343-52.

16. Terada M, Matsuda Y, Ogawa M, Matsui H, Satoh S. Effects of maternal factors on birth weight in Japan. J Pregnancy. 2013;2013:172395.

17. Berggren EK, Stuebe AM, Boggess KA. Excess maternal weight gain and large for gestational age risk among women with gestational diabetes. Am J Perinatol. 2015;32:251-6.

18. Yang S, Zhou A, Xiong C, Yang R, Bassig BA, Hu R, et al. Parental body mass index, gestational weight gain, and risk of macrosomia: a population-based case-control study in China. Paediatr Perinat Epidemiol. 2015;29:462-71.

19. Hantouzadeh S, Sheikh M, Bosaghzadeh Z, Ghotbizadeh F, Tarafdari A, Panahi $Z$, et al. The impact of gestational weight gain in different trimesters of pregnancy on glucose challenge test and gestational diabetes. Postgrad Med J. 2016:92:520-4.

20. MacDonald SC, Bodnar LM, Himes KP, Hutcheon JA. Patterns of gestational weight gain in early pregnancy and risk of gestational diabetes mellitus. Epidemiology. 2017;28:419-27.

21. Cho E-H, Hur J, Lee K-J. Early gestational weight gain rate and adverse pregnancy outcomes in Korean women. PLoS One. 2015;10:e0140376.

22. Baugh N, Harris DE, Aboueissa AM, Sarton C, Lichter E. The impact of maternal obesity and excessive gestational weight gain on maternal and infant outcomes in Maine: analysis of pregnancy risk assessment monitoring system results from 2000 to 2010. J Pregnancy. 2016;2016:5871313.

23. Mamun AA, Kinarivala M, O'Callaghan MJ, Williams GM, Najman JM, Callaway LK. Associations of excess weight gain during pregnancy with long-term maternal overweight and obesity: evidence from 21 y postpartum follow-up. Am J Clin Nutr. 2010;91:1336-41.

24. Xiong C, Zhou A, Cao Z, Zhang Y, Qiu L, Yao C, et al. Association of prepregnancy body mass index, gestational weight gain with cesarean section in term deliveries of China. Sci Rep. 2016;22, 6

25. Moll U, Olsson H, H M, Landin-Olsson M. Impact of pregestational weight and weight gain during pregnancy on long-term risk for diseases. PLoS One. 2017;2:e0168543.

26. Szczekala KM, Slusarska BJ, Gos AB. Motivational interviewing in obesity reduction. Med Stud/Studia Medyczne. 2017;33:73-80.
27. Samura T, Steer J, Michelis DL, Carroll L, Holland E, Perkins R. Factors associated with excessive gestational weight gain: review of current literature. Glob Adv Health Med. 2016;5:87-93.

28. Streuling I, Beyerlein A, Rosenfeld E, Schukat B, von Kries R. Weight gain and dietary intake during pregnancy in industrialized countries - a systematic review of observational studies. J Perinat Med. 2011;39:123-9.

29. Muktabhant B, Lawrie TA, Lumbiganon P, Laopaiboon M. Diet or exercise, or both, for preventing excessive weight gain in pregnancy (review). Cochrane Database Syst Rev. 2015;15:CD007145. https://doi.org/10.1002/14651858.CD007145.pub3.

30. Bärebring L, Brembeck $P$, Löf M, Brekke HK, Winkvist A, Augustin H. Food intake and gestational weight gain in Swedish women. Springerplus. 2016:5:377.

31. Lindberg S, Anderson C, Pillai P, Tandias A, Arndt B, Hanrahan L. Prevalence and predictors of unhealthy weight gain in pregnancy. WMJ. 2016;115:233-7.

32. Abbasalizad Farhangi M. Gestational weight gain and its related social and demographic factors in health care settings of rural and urban areas in Northwest Iran. Ecol Food Nutr. 2016;55:258-65.

33. Cohen AK, Kazi C, Headen I, Rehkopf DH, Hendrick CE, Patil D, et al. Educational attainment and gestational weight gain among U.S. mothers. Womens Health Issues. 2016;26:460-7.

34. Akgun N, Keskin HL, Ustuner I, Pekcan G, Avsar AF. Factors affecting pregnancy weight gain and relationships with maternal/fetal outcomes in Turkey. Saudi Med J. 2017;38:503-8.

35. Tielemans MJ, Erler NS, Leermakers ET, van den Broek M, Jaddoe WW, Steegers EA, et al. A priori and a posteriori dietary patterns during pregnancy and gestational weight gain: the generation R study. Nutrients. 2015;7:9383-99.

36. Rogozińska E, Marlin N, Jackson L, Rayanagoudar G, Ruifrok AE, Dodds J, et al. Effects of antenatal diet and physical activity on maternal and fetal outcomes: individual patient data meta-analysis and health economic evaluation. Health Technol Assess. 2017;21:1-158.

37. Schlaff RA, Holzman C, Mudd LM, Pfeiffer K, Pivarnik JM. Body mass index is associated with appropriateness of weight gain but not leisure-time physical activity during pregnancy. J Phys Act Health. 2014;11:1593-9.

38. Weisman CS, Hillemeier MM, Downs DS, Chuang CH, Dyer AM. Preconception predictors of weight gain during pregnancy: prospective findings from the Central Pennsylvania Women's Health Study. Womens Health Issues. 2010;(2):126-32.

39. Olson CM, Strawderman MS. Modifiable behavioral factors in a biopsychosocial model predict inadequate and excessive gestational weight gain. J Am Diet Assoc. 2003;103:48-54

40. Deputy NP, Sharma AJ, Kim SY, Hinkle SN. Prevalence and characteristics associated with gestational weight gain adequacy. Obstet Gynecol. 2015;125(4):773-81.

41. Huynh M, Borrell LN, Chambers EC. Maternal education and excessive gestational weight gain in new York City, 1999-2001: the effect of race/ ethnicity and neighborhood socioeconomic status. Matern Child Health J. 2014;18:138-45.

42. Borkowski W, Mielniczuk H. Wpływ wybranych czynników społecznych i zdrowotnych, w tym tempa przyrostu masy ciała w ciąży i masy przed ciążą, na małą masę urodzeniową noworodka. Ginekol Pol. 2008;79:415-21 (in polish).

43. Boylan S, Lallukka T, Lahelma E, Pikhart H, Malyutina S, Pajak A, et al. Socioeconomic circumstances and food habits in eastern, central and Western European populations. Public Health Nutr. 2011;14:678-87.

44. Stefler D, Pajak A, Malyutina S, Kubinova R, Bobak M, Brunner EJ. Comparison of food and nutrient intakes between cohorts of the HAPIEE and Whitehall II studies. Eur J Pub Health. 2016;26:628-34.

45. Szostak-Węgierek D, Cichocka A. Żywienie kobiet w ciąży. Wydawnictwo Lekarskie PZWL, Warszawa 2012, (in polish).

46. Suliga E. Nutritional behaviours of pregnant women in rural and urban environments. Ann Agric Environ Med. 2015;22:513-7.

47. Suliga E, Adamczyk-Gruszka O. Birth weight of newborns and health behaviours and haematological parameters of pregnant women - results of preliminary studies. Pediatr Endocrinol Diabetes Metab. 2015;23:6-14.

48. Lai JS, Soh SE, Loy SL, Colega M, Kramer MS, Chan JKY, et al. Macronutrient composition and food groups associated with gestational weight gain: the GUSTO study. Eur J Nutr. 2018;13. https://doi.org/10.1007/s00394-018-1623-3.

49. Stuebe AM, Oken E, Gillman MW. Associations of diet and physical activity during pregnancy with risk for excessive gestational weight gain. Am J Obstet Gynecol. 2009;201:e1-8.

50. Hillesund ER, Bere E, Haufen M, Øverby NC. Development of a new Nordic diet score and its association with gestational weight gain and fetal growth - a study performed in the Norwegian mother and child cohort study (MoBa). Public Health Nutr. 2014;17:1909-18. 
51. Wrottesley SV, Pisa PT, Norris SA. The influence of maternal dietary patterns on body mass index and gestational weight gain in urban black south African women. Nutrients. 2017;9:732.

52. Chuang $\mathrm{CH}$, Stengel MR, Hwang SW, Velott D, Kjerulff KH, Kraschniewski JL. Behaviours of overweight and obese women during pregnancy who achieve and exceed recommended gestational weight gain. Obes Res Clin Pract. 2014;8:e577-83.

53. Quinlivan JA, Julania S, Lam L. Antenatal dietary interventions in obese pregnant women to restrict gestational weight gain to Institute of Medicine recommendations: a meta-analysis. Obstet Gynecol. 2011;118:1395-401.

54. Uusitalo U, Arkkola T, Ovaskainen M-L, Kronberg-Kippilä C, Kenward MG, Veijola $\mathrm{R}$, et al. Unhealthy dietary patterns are associated with weight gain during pregnancy among Finnish women. Public Health Nutr. 2009;12:2392-9.

55. Fontaine P, Hellerstedt W, Dayman C, Wall M, Sherwood N. Evaluating body mass index specific trimester weight gain recommendations: differences between black and white women. J Midwifery Womens Health. 2012;57:327-35.

56. Heerman WJ, Bian A, Shintani A, Barkin SL. Interaction between maternal prepregnancy body mass index and gestational weight gain shapes infant growth. Acad Pediatr. 2014;14:463-70.

57. Favaretto AL, Duncan BB, Mengue SS, Nucci LB, Barros EF, Kroeff LR, et al. Prenatal weight gain following smoking cessation. Eur J Obstet Gynecol Reprod Biol. 2007;135:149-53.

58. Levine MD, Cheng Y, Cluss PA Marcus MD, Kalarchian MA. Prenatal smoking cessation intervention and gestational weight gain. Womens Health Issues. 2013;23:e389-93

59. Hulman A, Lutsiv O, Park CK, Krebs L, Beyene J, McDonald SD. Are women who quit smoking at high risk of excess weight gain throughout pregnancy? BMC Pregnancy Childbirth. 2016;16:263.

60. Veldheer S, Yingst J, Zhu J, Foulds J. Ten-year weight gain in smokers who quit, smokers who continued smoking and never smokers in the United States, NHANES 2003-2012. Int J Obes. 2015;39:1727-32.

61. Bush T, Lovejoy JC, Deprey M. The effect of tobacco cessation on weight gain, obesity and diabetes risk. Obesity (Silver Spring). 2016;24:1834-41.

62. Lan-Pidhainy $X$, Nohr EA, Rasmussen KM. Comparison of gestational weight gain-related pregnancy outcomes in American primiparous and multiparous women. Am J Clin Nutr. 2013;97:1100-6.

63. Hill B, Bergmeier H, McPhie S, Fuller-Tyszkiewicz M, Teede H, Forster D, et al Is parity a risk factor for excessive weight gain during pregnancy and postpartum weight retention? A systematic review and meta-analysis. Obes Rev. 2017;18:755-64.

64. Weisman CS, Hillemeier MM, Downs DS, Chuang CH, Dyer AM. Preconception predictors of weight gain during pregnancy: Prospective Findings from the Central Pennsylvania Women's Health Study. Womens Health Issues. 2010;20:126-32.

65. Rosal MC, Wang ML, Moore Simas TA, Bodenlos JS, Crawford SL, Leung K, et al. Predictors of gestational weight gain among white and Latina women and associations with birth weight. J Pregnancy. 2016;2016:8984928.

66. Papazian T, Abi Tayeh G, Sibai D, Hout H, Melki I, Rabbaa Khabbaz L. Impact of maternal body mass index and gestational weight gain on neonatal outcomes among healthy middle-eastern females. PLoS One. 2017:12:e0181255.

67. Restall A, Taylor RS, Thompson JMD, Flower D, Dekker GA, Kenny LC, et al. Risk factors for excessive gestational weight gain in a healthy, nulliparous cohort. J Obes. 2014;2014:148391.

68. Holowko N, Mishra G, Koupil I. Social inequality in excessive gestational weight gain. Int J Obes. 2014;38:91-6.

69. Campbell EE, Dworatzek PDN, Penava D, de Vrijer B, Gilliland J, Matthews Jl, et al. Factors that influence excessive gestational weight gain: moving beyond assessment and counselling. J Matern Fetal Neonatal Med 2016;29:3527-31.

70. Guilloty NI, Soto R, Anzalota L, Rosario Z, Cordero JF, Palacios C. Diet, prepregnancy BMl, and gestational weight gain in Puerto Rican women. Matern Child Health J. 2016:19:2453-61.

71. O'Brien EC, Alberdi G, McAuliffe FM. The influence of socioeconomic status on gestational weight gain: a systematic review. J Public Health (Oxf). 2017;7:1-15.

72. Holowko N, Chaparro MP, Nilsson K, Ivarsson A, Mishra G, Koupil I, et al. Social inequality in pre-pregnancy BMI and gestational weight gain in the first and second pregnancy among women in Sweden. J Epidemiol Community Health. 2015;69:1154-61.

73. Wronka I, Suliga E, Pawlińska-Chmara R. Socioeconomic determinants of underweight and overweight in female polish students in 2009. Anthrop Anz - J Biol Clinic Anthrop. 2012;(1):85-96.

Ready to submit your research? Choose BMC and benefit from:

- fast, convenient online submission

- thorough peer review by experienced researchers in your field

- rapid publication on acceptance

- support for research data, including large and complex data types

- gold Open Access which fosters wider collaboration and increased citations

- maximum visibility for your research: over $100 \mathrm{M}$ website views per year

At BMC, research is always in progress.

Learn more biomedcentral.com/submissions 